Evelien A. N. Oostdijk

Bastiaan H. J. Wittekamp

Christian Brun-Buisson

Marc J. M. Bonten

\section{Selective decontamination in European intensive care patients}

Received: 3 December 2011

Accepted: 12 December 2011

Published online: 1 February 2012

(C) The Author(s) 2012. This article is published with open access at Springerlink.com

E. A. N. Oostdijk · M. J. M. Bonten (

Department of Medical Microbiology, University Medical Center Utrecht, G04.614, PO box 85500, 3508 GA Utrecht,

The Netherlands

e-mail: M.J.M.Bonten@umcutrecht.nl

Tel.: +31-88-7557394

Fax: +31-88-7555132

\section{E. A. N. Oostdijk}

Department of Intensive Care Medicine, University Medical Center Utrecht, Utrecht, The Netherlands

B. H. J. Wittekamp · M. J. M. Bonten

Julius Center for Health Sciences and Primary Care, University

Medical Center Utrecht, Utrecht, The Netherlands

C. Brun-Buisson

INSERM U955, Université Paris Est-Créteil, Créteil, France

C. Brun-Buisson

Service de Réanimation Médicale, Assistance Publique-Hôpitaux de Paris, Groupe Henri Mondor, Créteil, France

C. Brun-Buisson

Faculté de Médecine, Université Paris-Est, Creteil, France

\section{Introduction}

Selective decontamination of the digestive tract (SDD) is both one of the most studied and one of the most debated preventive measures for critically ill patients in intensive care units (ICUs) (see box). After the first trials in hematology patients in the 1970s [1, 2], the concept was introduced in ICU populations in the 1980s [3], and frequently studied in the following decade [4]. Various different regimens were studied, including strictly oropharyngeal decontamination [selective oropharyngeal decontamination (SOD)] (see box). At the turn of the century there were more than 50 randomized, though mostly small and single-center, trials and several metaanalyses. The summarized conclusions from these studies were that SDD was associated with reductions of respiratory tract infections in ICUs with low levels of antibiotic resistance, but that improvement of patient outcome (i.e., better ICU survival) could be demonstrated in meta-analyses only $[5,6]$.

Since that time, numbers of new SDD studies declined and this measure was not widely adopted in European ICUs, mainly because the evidence for better patient outcome was considered not convincing, and because of the unknown-possibly detrimental-effects of prophylactic antibiotic use on antibiotic resistance development. The Netherlands became the exception to this rule, due to two studies, both demonstrating survival benefits of patients receiving SDD [7, 8]. In both studies, SDD was used as a unit-wide intervention in ICUs with low prevalence of antibiotic-resistant bacteria, and in both studies SDD was associated with lower, instead of higher, rates of antibiotic resistance. However, the absolute 28-day mortality reduction in the largest study was $3.5 \%$ (relative reduction was 13\%) and only determinable in a randomeffects logistic regression model with adjustment for baseline differences between study groups [8]. Moreover, in the latter study, SDD was equally effective in improving patient outcome as SOD.

The beneficial results of SDD and SOD obtained in Dutch ICUs raise the question of whether both measures could be equally beneficial in other European countries. Here, we address some methodological issues relevant to future attempts to quantify the effects of SDD or SOD in critically ill patients. 


\section{Study design}

The two studies in which SDD was associated with improved patient outcome tested SDD as a unit-wide intervention. In one study, SDD was administered to all patients who provided informed consent in one ICU during a 2-year study period $(n=466)$, and results were compared with those of another ICU (in the same hospital) where none of the patients received SDD $(n=468)$ [7]. Allocation of patients to either of the two wards was randomized if both units had beds available, but this was not further specified. In the other study, SDD was also administered to all patients eligible during a 6-month period in 13 ICUs $(n=2,045)$, and the results were compared with those obtained in 6-month periods in which all patients received either SOD $(n=1,904)$ or no topical antibiotics $(n=1,990)$ [8]. The latter was-at that time-considered standard of care. In this cluster-randomized crossover study, each of the 13 ICUs used SDD, SOD, and standard care during 6-month periods, with the order of interventions randomized per center. Importantly, in the latter study, there was no individualized randomization, which bears the risk, intrinsic to any clusterrandomized study, of biased patient inclusion [9]. Therefore, baseline characteristics related to patient prognosis must be included in the analysis.

There is an obvious reason to evaluate SDD and SOD as a unit-wide measure. Both measures aim to reduce bacterial carriage in individual patients, which may influence the risk of acquisition of bacterial colonization (followed by infection) of other patients. This patient dependency might reduce the true effects of interventions when patients with and without SDD (or SOD) are treated in the same unit [10]. As a result, failure to demonstrate beneficial outcome results in an individual patient randomized study may not reflect true effects when using these measures in all patients.

\section{Outcome measures}

A number of outcomes can be measured when studying infection prevention strategies in the ICU, including infection rates and antibiotic use, length of stay or of mechanical ventilation, and mortality rates in the ICU or at a fixed time-point (e.g., 28 days), or ventilator-free days (surviving) at 28 days. Which of these is most appropriate as the primary end-point in decontamination studies? It is widely believed that SDD and SOD exert their effects largely through prevention of respiratory tract infections, such as ventilator-associated pneumonia (VAP). As compared with SOD, the intestinal decontamination part of SDD seems to reduce the occurrence of ICU-acquired bacteremia with Gram-negative bacilli, but it is unlikely that this effect can be determinable in survival differences [11]. Diagnosing VAP is difficult and relies for an important part on microbiological culture results from respiratory samples [12]. The topical antibiotics applied in the oropharynx, though, aim to eradicate bacterial colonization of the upper respiratory tract, which will inevitably influence culture results. Only samples obtained from the distal parts of the lung that cannot be reached by the topical antibiotics will provide reliable diagnostic samples. Therefore, unambiguous, patientcentered outcomes such as survival should be used as endpoints when evaluating these interventions. Moreover, since recent studies have convincingly demonstrated that the attributable mortality of VAP is much lower than previously assumed, it is difficult to extrapolate a reduction in VAP incidence to improved patient survival [1315].

What should be the targeted mortality reduction? The relative reduction in 28-day mortality in the Dutch multicenter study was $13 \%$ for SDD and $11 \%$ for SOD, corresponding to absolute mortality reductions at day 28 of $3.5 \%$ and $2.7 \%$, respectively [8]. Based on these estimates, derived in units with low levels of antibiotic resistance, at least 2,000 patients per intervention group are needed to gain sufficient power. However, it would be highly relevant to determine outcome effects of these interventions on longer time scales, such as 90-day or 1-year survival, which may well enhance the number of patients needed. Furthermore, it is difficult to anticipate the magnitude of the effect on patient outcome in settings with different bacterial ecology, i.e., with higher prevalence of antibiotic-resistant bacteria. If the preventive effects on infection development are similar in such a setting, but attributable mortality of infection is higher because of more infections being caused by antibioticresistant bacteria, the effects on patient survival could be larger than those obtained in Dutch ICUs. In contrast, if fewer infections are prevented because of antibiotic resistance, it can be expected that effects on survival will be smaller (or even absent).

\section{Antibiotic resistance}

The global emergence of antibiotic resistance, especially among Enterobacteriaceae, necessitates enhanced infection control strategies, also in ICUs. In theory, SDD and SOD could have a synergistic effect with basic infection control measures such as hand hygiene and barrier precautions. Reductions of bacterial loads at places frequently contacted by nursing staff (i.e., the respiratory tract region), would reduce the likelihood of cross-transmission. However, the evidence on the effects of SDD on antibiotic resistance is highly conflicting. In settings with 


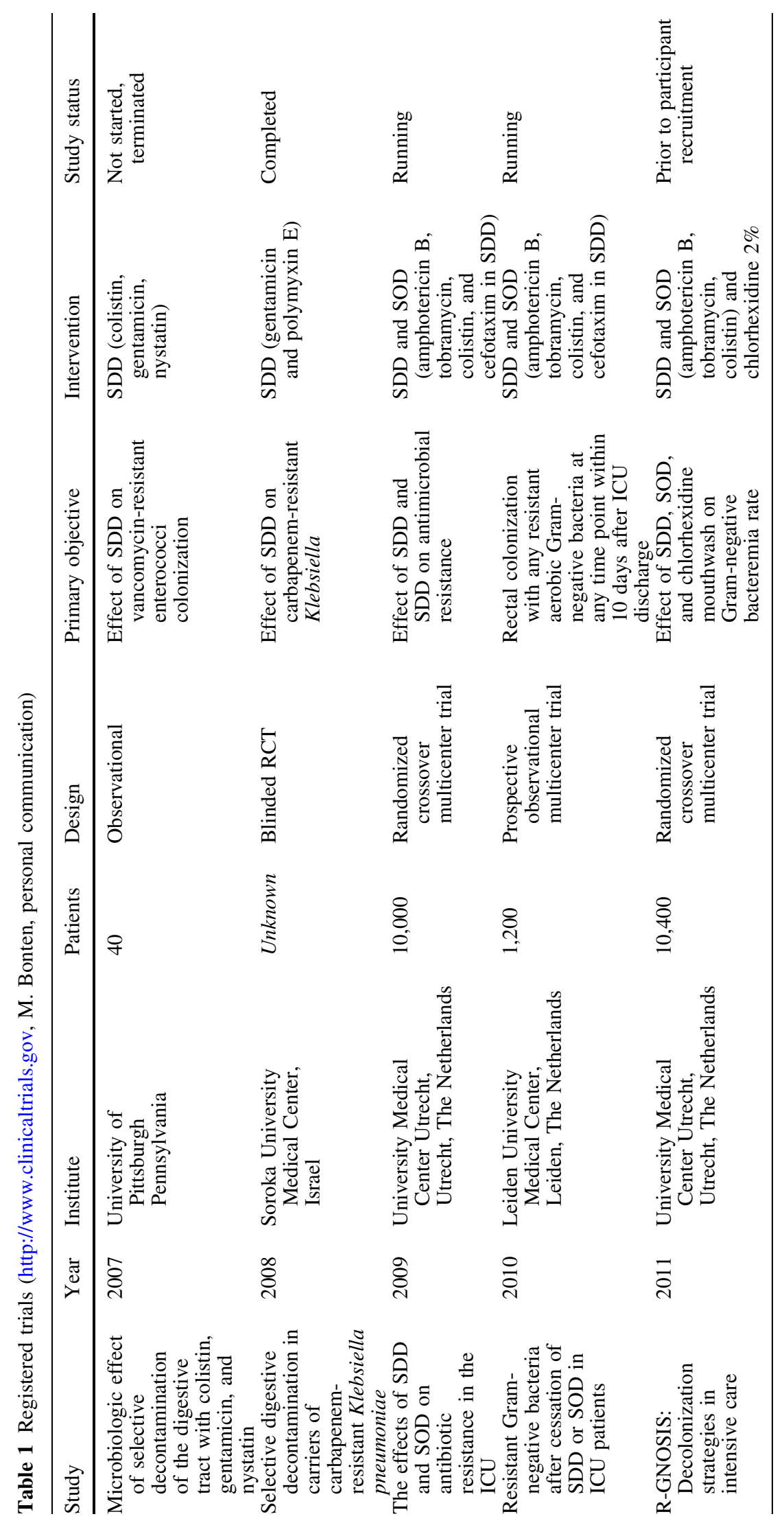


low levels of antibiotic resistance, such as Dutch ICUs, SDD and SOD were associated with lower rates of antibiotic-resistant Gram-negative bacteria [7, 16], and ongoing follow-up studies seem to confirm these findings (M. Bonten, unpublished data).

Less certain are the effects of topical antibiotics in settings with higher levels of resistance. There isalready "old"-evidence that SDD can help to control outbreaks with multiresistant Klebsiella strains [17], and persistently low levels of resistance have been reported from several centers using SDD for prolonged periods of time. In contrast, in some studies, use of SDD was associated with increasing rates of carriage and infections caused by antibiotic-resistant (mostly Gram-positive) pathogens [18-21].

Colistin is one of the antibiotics used in SDD and SOD. The recent rise of infections caused by carbapenemresistant Gram-negative bacteria makes this agent a lastresort antibiotic. It is therefore imperative to determine the effects of topical use of colistin on resistance development in Gram-negative bacteria. Furthermore, it is unknown whether patients recolonize with resistant bacteria when SDD is discontinued. Another aspect related to antibiotic resistance is the total amount of intravenous antibiotic use. According to the "classical" SDD protocol, all patients should receive intravenous antibiotics during the first 4 days. However, systemic antibiotics are also prescribed to virtually all eligible ICU patients, whether or not they are receiving SOD or no topical prophylaxis at all [8]. In the Dutch multicenter study, the total use of intravenous antibiotics (including the SDD component) was around $10 \%$ lower during SDD and SOD [8]. It is unknown to what extent such a reduction in systemic antibiotic use may influence resistance development.

\section{Other considerations}

A formal cost-benefit analysis of SDD does not exist. In the Dutch multicenter study it was estimated that the daily antibiotic costs of SDD and SOD were US $\$ 12$ and US \$1, respectively [8]. However, especially the price of amphotericin B has markedly risen in recent years. Today, the commercial price of SDD and SOD would be around $€ 200$ and $€ 40$ per day, respectively. Since the necessity of amphotericin B as a component of SDD has never been determined, it might be worthwhile to investigate SDD with other topical antimycotic agents (e.g., nystatin) [22-25].

Based on the Dutch multicenter study, one could conclude that SOD and SDD are equally effective in improving patient outcome. If confirmed, this implies that the improved outcome essentially results from the effects of the strategy on oropharyngeal bacterial carriage.
Chlorhexidine oropharyngeal care has also been associated with a 50\% reduction in VAP [26], quite similar to the reported effects of SOD [27], but the two interventions have never been compared directly. A recent metaanalysis suggests a dose-response relationship with optimal preventive effects of chlorhexidine oropharyngeal care when using a concentration of $2 \%$ [28]. If chlorhexidine is indeed equally effective as SDD and SOD, it would overcome all the potential problems with using topical antibiotics for prophylaxis in critically ill patients.

\section{Future studies}

Currently, there is only one large randomized clinical trial registered which evaluates the effects of SDD or SOD, again in Dutch ICUs (Table 1). Based on the favorable results obtained in Dutch ICUs, the logical next step seems to investigate SDD and SOD in settings with different bacterial ecology. However, when preparing such studies, some important lessons can be learned from the former studies. The beneficial effects of the interventions tested in individual studies have only been apparent when applied as unit-wide interventions. It is, therefore, advisable to apply this approach in any further study. Because of the difficulties in objectively diagnosing VAP and the fact that SDD and SOD cannot be applied in a doubleblind manner, it is advisable to use an unambiguous primary outcome, such as patient survival. Considering the small absolute reduction in 28-day mortality derived in Dutch ICUs, study groups should include at least 2,000 subjects. Detailed monitoring of antibiotic resistance is imperative, especially for colistin resistance; finally, studies comparing these interventions with $2 \%$ chlorhexidine oropharyngeal care are warranted.

SDD and SOD regimen

SDD consists of a mouth paste and of a suspension containing a mixture of nonabsorbable antibiotics applied four times daily until ICU discharge in the oropharynx and via a nasogastric tube in the gastrointestinal tract. In addition a systemic antibiotic is administered, usually a third-generation cephalosporin, during the first 4 days of ICU admission. The most widely studied regimen consists of tobramycin, colistin, and amphotericin B as topical antibiotics, and of cefotaxime as systemic prophylaxis. SOD only consists of the oropharyngeal application of the SDD mouth paste. Patients with expected length of ICU stay [ $48 \mathrm{~h}$ are eligible to receive SDD or SOD.

Acknowledgments M.J.M.B. is supported by The Netherlands Organization of Scientific Research (NWO-VICI 918.76.611); B.H.J.W., C.B-B. and M.J.M.B are supported by funding from the 
European Community (R-GNOSIS Integrated project [FP7/20072013] under grant agreement no. 282512).

Open Access This article is distributed under the terms of the Creative Commons Attribution License which permits any use, distribution, and reproduction in any medium, provided the original author(s) and the source are credited.

\section{References}

1. Dekker AW, Rozenberg-Arska M, Sixma JJ, Verhoef J (1981) Prevention of infection by trimethoprimsulfamethoxazole plus amphotericin B in patients with acute nonlymphocytic leukaemia. Ann Intern Med 95:555-559

2. Rozenberg-Arska M, Dekker AW, Verhoef J (1983) Colistin and trimethoprim-sulfamethoxazole for the prevention of infection in patients with acute non-lymphocytic leukaemia. Decrease in the emergence of resistant bacteria. Infection 11:167-169

3. Stoutenbeek CP, van Saene HK, Miranda DR, Zandstra DF (1984) The effect of selective decontamination of the digestive tract on colonisation and infection rate in multiple trauma patients. Intensive Care Med 10:185-192

4. Bonten MJ, Kullberg BJ, van Dalen R, Girbes AR, Hoepelman IM, Hustinx W, van der Meer JW, Speelman P, Stobberingh EE, Verbrugh HA, Verhoef J, Zwaveling JH (2000) Selective digestive decontamination in patients in intensive care. The Dutch working group on antibiotic policy. J Antimicrob Chemother 46:351-362

5. D'Amico R, Pifferi S, Leonetti C, Torri V, Tinazzi A, Liberati A (1998) Effectiveness of antibiotic prophylaxis in critically ill adult patients: systematic review of randomised controlled trials. BMJ 316:1275-1285

6. Liberati A, D'Amico R, Pifferi S, Torri V, Brazzi L, Parmelli E (2009) Antibiotic prophylaxis to reduce respiratory tract infections and mortality in adults receiving intensive care. Cochrane Database Syst Rev CD000022

7. de Jonge E, Schultz MJ, Spanjaard L, Bossuyt PM, Vroom MB, Dankert J, Kesecioglu J (2003) Effects of selective decontamination of digestive tract on mortality and acquisition of resistant bacteria in intensive care: a randomised controlled trial. Lancet 362:1011-1016
8. de Smet AM, Kluytmans JA, Cooper BS, Mascini EM, Benus RF, van der Werf TS, van der Hoeven JG, Pickkers $\mathrm{P}$, Bogaers-Hofman D, van der Meer NJ, Bernards AT, Kuijper EJ, Joore JC, Leverstein-van Hall MA, Bindels AJ, Jansz AR, Wesselink RM, de Jongh BM, Dennesen PJ, van Asselt GJ, te Velde LF, Frenay IH, Kaasjager K, Bosch FH, van Iterson M, Thijsen SF, Kluge GH, Pauw W, de Vries JW, Kaan JA, Arends JP, Aarts LP, Sturm PD, Harinck HI, Voss A, Uijtendaal EV, Blok HE, Thieme Groen ES, Pouw ME, Kalkman CJ, Bonten MJ (2009) Decontamination of the digestive tract and oropharynx in ICU patients. N Engl J Med 360:20-31

9. Puffer S, Torgerson D, Watson J (2003) Evidence for risk of bias in cluster randomised trials: review of recent trials published in three general medical journals. BMJ 327:785-789

10. Nijssen S, Bootsma M, Bonten M (2006) Potential confounding in evaluating infection-control interventions in hospital settings: changing antibiotic prescription. Clin Infect Dis 43:616-623

11. Oostdijk EA, de Smet AM, Kesecioglu J, Bonten MJ (2011) The role of intestinal colonization with gramnegative bacteria as a source for intensive care unit-acquired bacteremia. Crit Care Med 39:961-966

12. Brun-Buisson C, Fartoukh M, Lechapt E, Honore S, Zahar JR, Cerf C, Maitre B (2005) Contribution of blinded, protected quantitative specimens to the diagnostic and therapeutic management of ventilator-associated pneumonia. Chest 128:533-544

13. Bekaert M, Timsit JF, Vansteelandt S, Depuydt P, Vesin A, Garrouste-Orgeas M, Decruyenaere J, Clec'h C, Azoulay E, Benoit D (2011) Attributable Mortality of Ventilator Associated Pneumonia: A Reappraisal Using Causal Analysis. Am J Respir Crit Care Med 184:1133-1139

14. Melsen WG, Rovers MM, Koeman M, Bonten MJ (2011) Estimating the attributable mortality of ventilatorassociated pneumonia from randomized prevention studies. Crit Care Med $39: 2736-2742$
15. Nguile-Makao M, Zahar JR, Francais A, Tabah A, Garrouste-Orgeas M, Allaouchiche B, Goldgran-Toledano D, Azoulay E, Adrie C, Jamali S, Clec'h C, Souweine B, Timsit JF (2010) Attributable mortality of ventilatorassociated pneumonia: respective impact of main characteristics at ICU admission and VAP onset using conditional logistic regression and multi-state models. Intensive Care Med 36:781-789

16. de Smet AM, Kluytmans JA, Blok HE, Mascini EM, Benus RF, Bernards AT, Kuijper EJ, Leverstein-van Hall MA, Jansz AR, de Jongh BM, van Asselt GJ, Frenay IH, Thijsen SF, Conijn SN, Kaan JA, Arends JP, Sturm PD, Bootsma MC, Bonten MJ (2011) Selective digestive tract decontamination and selective oropharyngeal decontamination and antibiotic resistance in patients in intensive-care units: an open-label, clustered group-randomised, crossover study. Lancet Infect Dis 11:372-380

17. Brun-Buisson C, Legrand P, Rauss A, Richard C, Montravers F, Besbes M, Meakins JL, Soussy CJ, Lemaire F (1989) Intestinal decontamination for control of nosocomial multiresistant gram-negative bacilli. Study of an outbreak in an intensive care unit. Ann Intern Med 110:873-881

18. de La Cal MA, Cerda E, Garcia-Hierro $\mathrm{P}$, van Saene HK, Gomez-Santos D, Negro E, Lorente JA (2005) Survival benefit in critically ill burned patients receiving selective decontamination of the digestive tract: a randomized, placebo-controlled, double-blind trial. Ann Surg 241:424-430

19. Heininger A, Meyer E, Schwab F, Marschal M, Unertl K, Krueger WA (2006) Effects of long-term routine use of selective digestive decontamination on antimicrobial resistance. Intensive Care Med 32:1569-1576

20. Lingnau W, Berger J, Javorsky F, Fille M, Allerberger F, Benzer H (1998) Changing bacterial ecology during a five-year period of selective intestinal decontamination. J Hosp Infect 39:195-206 
21. Verwaest C, Verhaegen J, Ferdinande P, Schetz M, Van den Berghe G, Verbist L, Lauwers P (1997)

Randomized, controlled trial of selective digestive decontamination in 600 mechanically ventilated patients in a multidisciplinary intensive care unit. Crit Care Med 25:63-71

22. Cockerill FR 3rd, Muller SR, Anhalt JP, Marsh HM, Farnell MB, Mucha P, Gillespie DJ, Ilstrup DM, Larson-Keller JJ, Thompson RL (1992) Prevention of infection in critically ill patients by selective decontamination of the digestive tract. Ann Intern Med 117:545-553

23. Flaherty J, Nathan C, Kabins SA, Weinstein RA (1990) Pilot trial of selective decontamination for prevention of bacterial infection in an intensive care unit. J Infect Dis 162:1393-1397
24. Ruza F, Alvarado F, Herruzo R, Delgado MA, Garcia S, Dorao P, Goded F (1998) Prevention of nosocomial infection in a pediatric intensive care unit (PICU) through the use of selective digestive decontamination. Eur $\mathbf{J}$ Epidemiol 14:719-727

25. Wiener J, Itokazu G, Nathan C, Kabins SA, Weinstein RA (1995) A randomized, double-blind, placebocontrolled trial of selective digestive decontamination in a medical-surgical intensive care unit. Clin Infect Dis 20:861-867

26. Koeman M, van der Ven AJ, Hak E, Joore HC, Kaasjager K, de Smet AG, Ramsay G, Dormans TP, Aarts LP, de Bel EE, Hustinx WN, van der Tweel I, Hoepelman AM, Bonten MJ (2006)

Oral decontamination with chlorhexidine reduces the incidence of ventilator-associated pneumonia. Am J Respir Crit Care Med 173:1348-1355
27. Bergmans DC, Bonten MJ, Gaillard CA, Paling JC, van der Geest S, van Tiel FH, Beysens AJ, de Leeuw PW, Stobberingh EE (2001) Prevention of ventilator-associated pneumonia by oral decontamination: a prospective, randomized, double-blind, placebocontrolled study. Am J Respir Crit Care Med 164:382-388

28. Labeau SO, Van de Vyver K, Brusselaers N, Vogelaers D, Blot SI (2011) Prevention of ventilatorassociated pneumonia with oral antiseptics: a systematic review and meta-analysis. Lancet Infect Dis 11:845-885 